\title{
O DISCURSO DA SUPREMACIA BRANCA E $O$ ESPORTE: UM ESTUDO A PARTIR DE TEXTOS E COMENTÁRIOS NA INTERNET
}

\author{
THE DISCOURSE OF WHITE SUPREMACY AND SPORTS: A STUDY BASED ON \\ INTERNET TEXTS AND COMMENTS
}

\author{
EL DISCURSO DE LA SUPREMACÍA BLANCA Y EL DEPORTE: UN ESTUDIO A \\ PARTIR DE TEXTOS Y COMENTARIOS EN INTERNET
}

Marcio Antonio Tralci Filho*, Alessandro de Oliveira dos Santos*

Palavras chave:

Racismo.

Esportes.

Internet.

Keywords:

Racism.

Sports.

Internet.

\begin{abstract}
Resumo: Este artigo se propõe a analisar a persistência e a reprodução da supremacia branca a partir de comentários na internet sobre esporte. Foram selecionados comentários de cinco textos publicados entre 2009 e 2016 que abordaram o tênis, escolhido por ser historicamente um esporte com hegemonia de atletas brancos, e, mais especificamente, pelo desempenho da atleta Serena Williams. Como resultados, observamos que a supremacia branca se faz presente no esporte, mesmo quando não há referências diretas à raça-etnia, na deslegitimação de denúncias e nos olhares sobre performances e corpos brancos e negros. Ademais, constatou-se que o esporte é também local de produção de discursos sobre a supremacia branca, uma vez que a ênfase no biológico e nos essencialismos culturais incentiva interpretações sobre a presença/ausência e desempenho de atletas brancos e negros que revisitam mitos políticos construídos pelo racismo científico do século XIX.
\end{abstract}

\begin{abstract}
This article looks into the persistence and reproduction of white supremacy from internet comments about sport. Comments were selected from five texts published between 2009 and 2016 about Tennis, chosen for being a sport with historical hegemony of white athletes and more specifically because of Serena Williams's performance. We found that white supremacy is present in sports, even when there are no direct references to race-ethnicity, when complaints are delegitimized and on the views of white and black bodies and performances. Moreover, sport is also a place for discourse production about white supremacy since the emphasis on biological aspects and cultural essentialisms encourages interpretations on the presence/absence and the performance of white and black athletes that revisit political myths built by nineteenth century scientific racism.
\end{abstract}

Palabras clave:

Racismo.

Deportes.

Internet.

Resumen: Este artículo tiene como objetivo analizar la persistencia y la reproducción de la supremacía blanca a partir de comentarios sobre deporte en internet. Seleccionamos comentarios de cinco textos publicados entre 2009 y 2016 abordando el Tenis, escogido por ser históricamente un deporte con hegemonía de atletas blancos, y más específicamente, el rendimiento de la atleta Serena Williams. Como resultado, se encontró que la supremacía blanca está presente en el deportes, incluso cuando no hay referencias directas a la raza-etnia, en la deslegitimización de denuncias y en las miradas sobre las performances y cuerpos de blancos y negros. Además, se constató que el deporte es también un lugar de producción de discursos sobre la supremacía blanca, ya que el énfasis en los aspectos biológicos y en los esencialismos culturales alienta interpretaciones sobre la presencia/ausencia y el rendimiento de atletas blancos y negros, revisitando mitos políticos construidos por el racismo científico del siglo XIX.
*Universidade de São Paulo. São Paulo, SP, Brasil. E-mail: matfilho@usp.b

Recebido em: 05-03-2016 Aprovado em: 12-08-2016 (c) (i) () Licence 


\section{INTRODUÇÃO}

O esporte enquanto prática social tem se configurado como um campo instigante para discussão das relações raciais. Nos últimos tempos, ofensas de cunho racial proferidas por atletas, torcedores(as) e dirigentes durante jogos ou em decorrência deles têm ganhando espaço nos debates sobre o esporte.

Em geral, o foco desses debates privilegia a atuação dos indivíduos envolvidos, ou seja, quem proferiu e quem foi alvo. Isso ocorreu, por exemplo, em relação às ofensas de cunho racial contra o goleiro Aranha da equipe de futebol do Santos em partida disputada em agosto de 2014 com a equipe do Grêmio, em Porto Alegre. Após reagir às ofensas, recaíram sobre 0 atleta críticas por ele ter levado o caso à esfera jurídico-penal. Aranha foi acusado de ser vingativo em diversos comentários sobre o caso que circularam na internet por não encerrar a ação judicial mesmo após um pedido formal de desculpas da torcedora que o chamou de "macaco". Os comentários também aludiam à deslegitimação do sofrimento do atleta, alegando que as ofensas de cunho racial se deram em função do "calor do jogo" e que é comum atletas serem ofendidos por torcedores.

Comentários e interações comunicacionais produzidos na internet e veiculados através de sites de notícias, blogs e redes sociais vêm recebendo atenção de pesquisadores tanto como objeto de pesquisa, quanto como ferramenta para acessar e analisar discursos sobre os mais variados temas.

Assunção e Matos (2014) realizaram grupos focais com 20 portugueses jovens investigando seus posicionamentos sobre o uso da rede social Facebook e seus benefícios e riscos. As autoras constataram que há maior facilidade dos jovens se comunicarem pela rede social do que em conversas face a face, devido à facilidade de se expressarem sem precisar lidar com a reação imediata do(a) interlocutor(a).

Biondo (2015) utilizou o Facebook como ferramenta para acessar discursos sobre gênero e sexualidade nos comentários de duas comunidades da rede social, uma feminista e uma anti-homofóbica. A autora encontrou discursos que se aproximam de uma visão essencialista das identidades sexuais e de gênero em ambas as comunidades investigadas.

Recuero e Soares (2013), por sua vez, construíram uma metodologia de pesquisa própria para postagens na internet, a Análise do Discurso Mediado pelo Computador. As autoras analisaram o tema da violência em comentários de três postagens de uma página com mais de 500 mil seguidores no Facebook: "Diva Depressão". Constataram que os discursos veiculados apresentam argumentos na direção da redução do impacto da violência sofrida, de modo a considerá-la como parte da permissividade do humor, desacreditando os discursos mais críticos e contribuindo para a reprodução de estereótipos e para legitimação da violência.

O ambiente virtual também tem sido objeto de investigação no campo da Educação Física e Esporte. Cruz Junior, Fermino e Pires (2015), por exemplo, investigaram publicações e comentários do blog do jornalista Juca Kfouri sobre a Copa do Mundo de 2014, evidenciando a potencialidade dos meios digitais, em relação aos meios de comunicação de massa, no que se refere ao agendamento midiático esportivo, ou seja, às tentativas de pautar temas referentes ao mundo do esporte na esfera pública. Já Grespan e Goellner (2014) analisaram comentários de sites e blogs sobre a participação da lutadora transgênero Fallon Fox em eventos femininos 
de Mixed Martial Arts. As autoras identificaram discursos contrários à presença da atleta nas competições com base em argumentos de ordem biomédica e de aversão às pessoas transexuais.

A virtualidade oferece um enorme potencial para identificação e análise de discursos acerca de um determinado fato, fenômeno ou tema. No Brasil, onde as ofensas de cunho racial configuram um crime previsto em lei, torna-se relevante a análise desses comentários, visto que no ambiente virtual os discursos são proferidos voluntariamente. Ou seja, a internet é fonte de discursos públicos e espontâneos, configurando um terreno fértil para descrever e analisar posicionamentos sobre as relações raciais em uma sociedade constituída sobre uma supremacia branca.

Por supremacia branca entendemos o sistema de produção, reprodução e perpetuação de hierarquias sociais baseadas na racialização de grupos humanos. Esse sistema é fomentado por uma ideologia que defende a superioridade ética, estética, intelectual e espiritual das pessoas brancas, estabelecendo a branquitude, a identidade racial das pessoas brancas, como referência universal de humanidade (SCHUCMAN, 2012).

Ainda que desenvolvido em países anglófonos, o conceito de white supremacy (supremacia branca) não está circunscrito somente à experiência histórica dos países de colonização britânica, que elaboraram legislação segregacionista pós-escravidão, como as leis Jim Crow nos EUA ou a Lei do Apartheid na África do Sul e na Austrália. Aplica-se também aos países de colonização ibérica nas Américas com suas estratégias políticas de embranquecimento populacional através do incentivo à imigração branco-europeia e restrições à imigração de grupos não brancos (CARNEIRO, 2012). É nessa perspectiva que Mills (2003) interpreta a supremacia branca como um sistema de dominação política pela branquitude cuja origem se deu no projeto de expansão colonialista europeu, constituindo-se, portanto, como um fenômeno global.

Em relação a esse sistema de hierarquização no contexto esportivo, as leituras de Cyril Lionel Robert James e Pierre Bourdieu nos orientam. Cyril Lionel Robert James foi 0 primeiro a escrever um livro com a temática "Raça e Esporte": o relato autobiográfico Beyond a Boundary (JAMES, 1993), sobre sua experiência com o críquete. Nele, duas ideias principais emergem: 1) os ideais meritocráticos e de justiça liberal, evocados pelo esporte, não impedem o críquete de ser uma instituição livre de racismo; e 2) essa dinâmica apresentada no esporte possui paralelos com o colonialismo, bem como com as lutas anticoloniais e antirracistas. Ou seja, James (1993) considera o esporte como um território contestado das relações raciais (HARTMANN, 2003; CARRINGTON, 2013).

Já Bourdieu (2004a, 2004b) chama atenção para a necessidade de aproximar as diversas manifestações esportivas dos espaços sociais nelas manifestos, uma vez que cada esporte representa uma posição particular dentro do universo dos esportes. Nessa perspectiva, um dos indicadores que informam sobre os aspectos distintivos dos esportes está nas relações de poder estabelecidas pela presença/ausência e disposição dos corpos nas práticas esportivas, cabendo a pergunta sobre como os corpos racializados são percebidos no esporte.

Assim, esse artigo teve como objetivo descrever e analisar narrativas circulantes em comentários de notícias na internet evidenciando a persistência e a reprodução da supremacia branca no esporte com enfoque no tênis. 
O tênis é um esporte com estrutura institucional consolidada internacionalmente e reconhecido historicamente como praticado e gerenciado, em sua maioria, por pessoas brancas. Nessa estrutura institucional, duas mulheres negras têm se destacado nos últimos anos dentre as melhores tenistas do mundo, as irmãs Venus e Serena Williams, configurando um lócus relevante de identificação e análise dos discursos proferidos acerca dessa presença e da supremacia branca no âmbito desse esporte.

Venus e Serena Williams são alvo de vigilância e sinal de alerta por não serem bemvindas em um espaço que não lhes parece pertencer, como publicamente é reiterado. Suas ações dentro e fora das quadras são vistas sob a óptica da suspeita, não permitindo espaço para outros pontos de vista e afetando sua credibilidade, conforme já foi apontado por Douglas (2002; 2005). A comoção que as declarações e atitudes, ou mesmo a simples presença, das irmãs causa nas pessoas envolvidas com o tênis se assemelha à relação que Bento (2002) estabelece entre branquitude e medo. A autora associa o medo branco à construção da imagem do outro a partir da projeção de si mesmo e, desse modo, a noção de que quando um espaço branco é tomado pelos negros evidencia a fragilidade da identidade branca hegemônica. Assim, frente a uma dinâmica social de poder que exige uma delimitação a respeito do que pertence a "si" e do que pertence ao "outro", a antipatia direcionada a Serena e Venus fortalece o pacto racial tácito entre pessoas brancas. Em outras palavras, a afirmação da branquitude é realizada a partir de uma permissividade das pessoas brancas em vigiar e condenar Venus e Serena abertamente em "conversas sobre raça" (DOUGLAS, 2012). Como afirma Douglas (2005), a mensagem de supremacia branca foi e é construída e comunicada através da marginalização de Serena e Venus.

Venus e Serena são constantemente colocadas no lugar do "outro" racializado. Schultz (2005) afirma que a tensão entre a negritude das tenistas e a supremacia branca no tênis produz discursos racializados a respeito de seus corpos pela indústria midiática que evidenciam as lógicas pelas quais são construídas as relações raciais na contemporaneidade, ou seja, um racismo que "não enxerga cor" (color-blind racism). Trata-se da atualização constante dos modos de expressar preconceitos e praticar discriminação para além do explícito e que resultam na manutenção estrutural das condições sociais favoráveis às pessoas brancas em detrimento das pessoas não brancas, principalmente as negras (BONILLA-SILVA, 2014).

Se, por um lado, a presença e o sucesso competitivo delas são apropriados pelas instituições esportivas para imprimir uma aparência de valorização à diversidade e igualdade de oportunidade, por outro, os processos de racialização aos quais ambas as tenistas são submetidas continuam à margem do debate público. $O$ que dilui, por conseguinte, o fato de haver um acesso restrito ao tênis às pessoas negras e a ineficácia das federações em reverter esse quadro (SCHULTZ, 2005). Desse modo, a presença de Serena Williams, ao invés de evidenciar o tênis como um espaço racializado que privilegia atores (atletas, treinadores, dirigentes e torcedores) brancos, acaba sendo interpretada como uma amostra da suposta ausência de racismo nesse esporte (DOUGLAS, 2005).

Nessa direção, Spencer (2012) utilizou o conceito de "ficções sinceras" - de inspiração bourdiesiana - para denominar as tentativas de deslegitimação das denúncias e do boicote das atletas ao Torneiro Aberto de Indian Wells em razão de ofensas de cunho racial proferidas pelo público na edição de 2001. De acordo com a autora, a supremacia branca, manifesta no campo 
esportivo do tênis, é de tal modo eficaz que permite às pessoas brancas se observarem fora da dinâmica das relações raciais ao mesmo tempo em que operam discursos de ódio baseado no pertencimento racial dos(as) atletas.

A noção de "ficções sinceras" utilizada por Spencer (2012) se relaciona ao conceito de "mito político" de Raoul Girardet (1987). Se, por um lado, a construção de ficções por parte de pessoas brancas é uma estratégia de manutenção de privilégios - em especial, do privilégio de se manifestar pejorativamente sobre pessoas negras -, por outro, é inescapável o fato de que essas manifestações reavivam, de uma maneira ou de outra, mitos, falseamentos da realidade construídos em um contexto de dominação e subordinação política baseada na racialização de grupos humanos.

Persiste um amparo social para o racismo que não se dá porque as pessoas se assumem preconceituosas ou se manifestam explicitamente enquanto tal. Mas, porque uma vez construído em um contexto histórico-político específico, a noção de supremacia branca permaneceu inscrita no imaginário social e fundou-se como um mito. Como diz Girardet (1987, p. 51): "O mito existe independentemente de seus usuários eventuais; impõe-se a eles bem mais do que eles contribuem para sua elaboração."

Um dos mitos mais relevantes a respeito dos tensionamentos entre os discursos da supremacia branca e os corpos de mulheres negras está relacionado à história de Sarah Baartman. Também conhecida pejorativamente como "Vênus Hotentote", Sarah Baartman (1789-1815) era uma mulher do povo Khoisan (atual África do Sul) que foi capturada e levada para Inglaterra e França para ser exposta nua como atração em freak shows.

Suas nádegas e genitália eram vistas com curiosidade, fascínio, escárnio e repulsa e foram interpretadas como prova física de seu distanciamento da humanidade. Esse discurso contribuiu para a construção de um imaginário masculino europeu sobre a corporeidade das mulheres africanas (IFEKWUNIGWE, 2009). A exploração do seu corpo foi base para a construção científico-biológica do conceito de raça (FERREIRA; HAMLIM, 2010). No espectro da dicotomia da Natureza em oposição à Cultura, Sarah e, por extensão, todo seu povo, eram vistos como mais próximos da primeira.

Nesse sentido, o próprio esporte pode contribuir para reforçar privilégios e desvantagens conforme o pertencimento racial dos(as) atletas. $O$ fato de ser uma prática diretamente relacionada ao esforço físico e à exposição das potencialidades corporais contribui para que o esporte seja entendido a partir de concepções biológicas e funcionais (HYLTON, 2008). Desse modo, as explicações para as diferenças de desempenhos e as desigualdades de acesso associam-se facilmente ao determinismo biológico ou social, sendo, por conseguinte, uma prática social mais permeável ao racismo pseudocientífico e à legitimação de desigualdades. Ademais, é recorrente a noção de que o esporte é um espaço de justiça e igualdade de oportunidades. Em última instância, um lugar no qual os vencedores e perdedores são definidos a partir do esforço individual ou das somas dos esforços individuais. Entretanto, tal interpretação do esporte enquanto "parábola" de ganho e recompensa através de esforço também pode contribuir para encobrir relações de dominação e subordinação (BIRREL, 1989).

1 Ferreira e Hamlim (2010) afirmam que os colonizadores holandeses do século XVII denominavam "Hot-en-tot" diversos povos sul-africanos cujos dialetos possuíam cliques. Hotentote era uma onomatopeia para se referir à gagueira e também para designar a quem consideravam como inferior intelectual ou culturalmente. 


\section{METODOLOGIA}

Trata-se de um estudo qualitati vo do tipo descritivo exploratório utilizando comentários de textos jornalísticos e de colunas e blogs sobre esportes. Foram selecionados cinco textos publicados entre os anos de 2009 e 2016, sendo um publicado em 2009, três em 2015 e um em 2016.

O primeiro texto é de autoria de Djamila Ribeiro, mestra em Filosofia Política e colaboradora do blog Blogueiras Negras, e foi publicado no site da revista Carta Capital em 26 de agosto de 2015 com o título "Comentaristas esportivos: respeitem Serena Willians". No texto, Djamila emite seu ponto de vista sobre o modo como os comentaristas esportivos se referem à tenista Serena Williams nas transmissões televisivas.

O segundo texto é de autoria de Paulo Cleto e foi publicado em seu blog pessoal em 5 de outubro de 2009, com o título "Saco de gatas". Cleto é uma pessoa influente no esporte. Foi Diretor de Tênis do Esporte Clube Pinheiros em São Paulo, atuou como técnico da Equipe Olímpica das edições de Seul (1988), Barcelona (1992) e Atlanta (1996), foi chefe da Equipe dos Jogos Pan-americanos de Winnipeg (1999), fundou a primeira academia de tênis no país, em 1973, além de ter trabalhado em diversos veículos de comunicação como colunista, comentarista e produtor. Em seu texto, ele critica os critérios da WTA (Associação de Tênis Feminino) para a elaboração do ranking daquele ano, visto que Serena Williams havia ganhado mais torneios do "Grand Slam" que a tenista Dinara Safina e, mesmo assim, esta figurava como primeira colocada.

O terceiro e o quarto textos apresentam narrativas sobre Serena Williams em dois momentos distintos: em uma vitória e em uma derrota, permitindo observar como são construídos os discursos nas duas situações. Um deles, cujo título é "Serena vence em Wimbledon pela sexta vez e completa o 'Serena Slam", foi publicado pelo portal de notícias UOL, na seção de Esportes, em 11 de julho de 2015. O outro é a matéria intitulada "Serena leva virada improvável na semifinal e perde maior chance de fazer o Grand Slam", publicada pelo site ESPN.com.br no dia 11 de setembro de 2015, após uma derrota da tenista para a italiana Roberta Vinci.

Por fim, um quinto texto foi considerado para análise após observarmos que acusações sobre uma suposta superdosagem de substâncias ilícitas (doping) por Serena Williams eram recorrentes entre os comentaristas na internet. Trata-se do texto "Sharapova anuncia que foi pega em exame antidoping e está suspensa", publicado no portal UOL de 7 de março de 2016, que anuncia o resultado do doping e a decorrente declaração pública da tenista branca Maria Sharapova, frequente adversária de Williams. Esse texto foi escolhido com o intuito de analisar as implicações nas relações raciais quando uma atleta branca, de destaque internacional semelhante a Serena Williams, é acusada de doping.

A comparação, a partir de textos jornalísticos, entre discursos públicos que abordam a corporeidade e performance de Serena em relação a tenistas brancas, bem como o papel simbólico de Serena na desestabilização de discursos da supremacia branca, já foram analisados em outros estudos (DOUGLAS, 2005; SCHULTZ, 2005; IFEKWUNIGWE, 2009; DOUGLAS, 2012). Para além desses trabalhos mencionados, o presente artigo pretende contribuir com essa discussão e ampliar seu escopo metodológico ao incluir a realização 
de uma análise sobre a recepção desses discursos por leitores de artigos jornalísticos e de colunas opinativas.

O critério para seleção dos textos e comentários foi que não houvesse necessidade de cadastramento nos sites eletrônicos para obtê-los, sendo o material de domínio público (FONSECA, 2014). Por serem materiais que permitem consulta direta e disponibilidade irrestrita, apresentamos os comentários e a identificação dos usuários (nomes e fotos) tais como constavam nas fontes à época da pesquisa. Devido ao seu caráter opinativo, eventualmente os conteúdos dos textos das colunas e blogs foram considerados e incluídos como comentários.

Com base no procedimento proposto por Fonseca (2014), a análise de conteúdo do material coletado foi realizada com atenção para as expressões em letra maiúscula (caixa alta), expressões de risos, número de aprovações (curtidas) e desaprovações dos comentários, entre outras expressões características de interações na internet. A análise de conteúdos dos comentários voltou-se para as narrativas que expressavam hierarquias baseadas na lógica da supremacia branca, mas sem se referir diretamente à raça, como as imagens historicamente dominantes sobre a corporeidade de atletas. O recorte temporal - seleção de textos e comentários publicados em 2009 e 2016 - foi proposital no sentido de identificar a permanência ou não ao longo do tempo de discursos associados à supremacia branca em relação aos corpos racializados.

Em função do espaço e do número de palavras concernentes à formatação do texto na forma de artigo, optou-se por não apresentar uma análise da totalidade dos comentários encontrados nas notícias e colunas. Entretanto, em que pese a essa limitação, cabe ressaltar que nas seções de comentários dos textos foram observadas interações entre usuários, os quais, por algumas vezes, estabeleceram diálogos que se desviaram do tema principal do texto, além de comentários críticos às narrativas aqui analisadas, ou que não se relacionavam ao conteúdo da publicação, ou mesmo que foram enviados por engano ou em duplicata. Por conseguinte, dentre os comentários, buscou-se selecionar aqueles que contribuíam para evidenciar discursos que reforçam a supremacia branca no esporte.

\section{RESULTADOS}

\subsection{Naturalização e isenção de preconceito}

Análise dos comentários do texto de Ribeiro (2015)

Em seu texto, Djamila Ribeiro aponta uma série de expedientes discursivos dos comentaristas em jogos da tenista Serena Williams que demonstram tratamento hierarquicamente diferenciado em relação a outras tenistas, que são brancas, evidenciando uma "mídia esportiva racista, machista, antiética e despreparada". O texto recebeu 116 comentários, alguns questionando os argumentos levantados pela autora, dos quais selecionamos dois para a análise: 
Figura 1 - Seleção de comentários do texto de Ribeiro

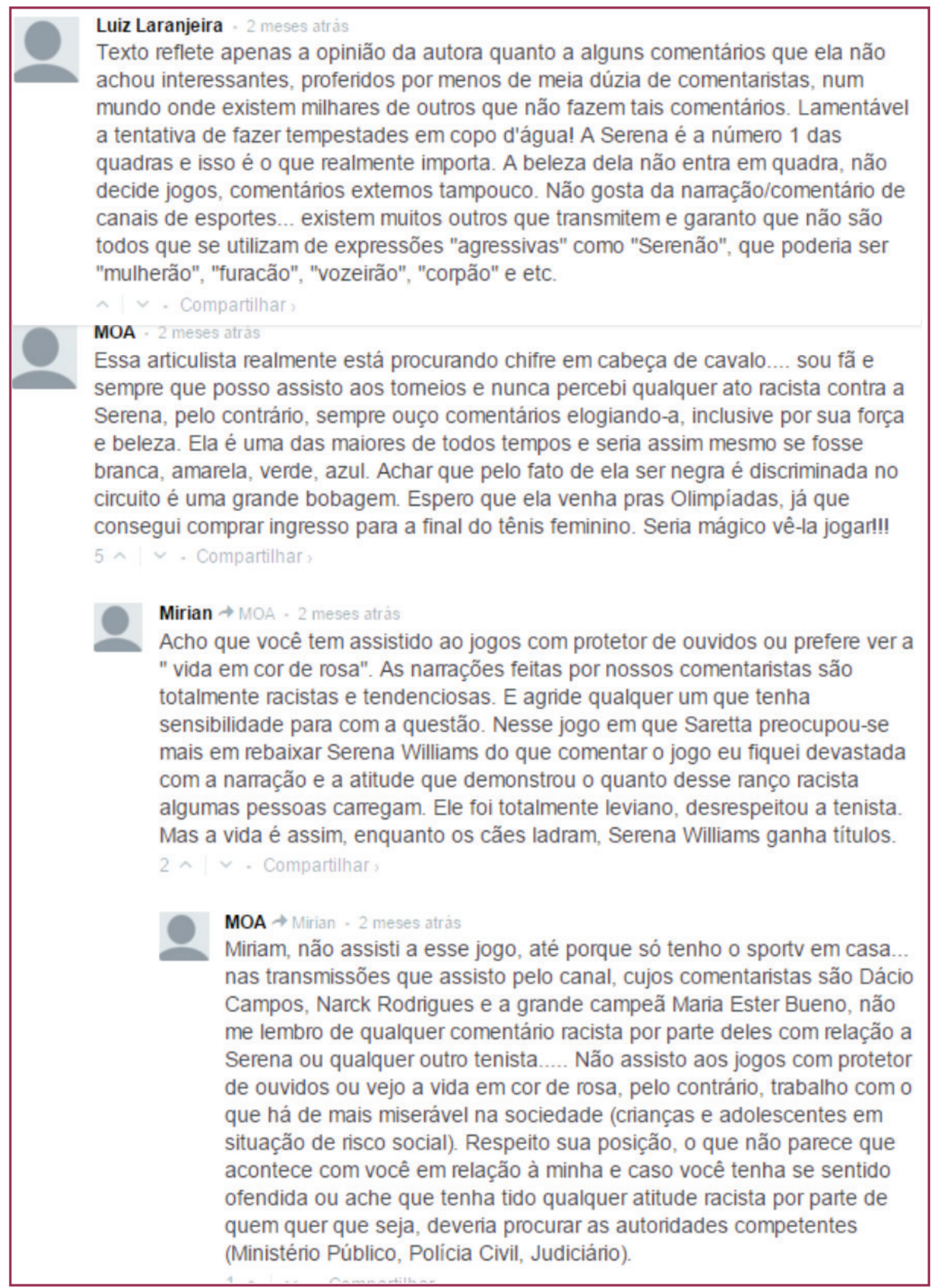

Fonte: RIBEIRO, 2015.

Esses comentários são representativos das narrativas dos leitores que discordavam da autora, os quais se alternavam com comentários breves de apoio ao texto principal. Em geral, os comentários com textos mais longos que reforçaram os argumentos de Ribeiro (2015), como, por exemplo, o de "Mirian", se deram em resposta aos comentários de desaprovação. Tais comentários evidenciam estratégias de desqualificação dos argumentos da autora individualizando o problema: ora dizem que se trata apenas de uma implicância, ora a contraprova é a opinião deles próprios de que não se trata de algo a ser levado em consideração. É "tempestade em copo d'água", "procurar chifre na cabeça de cavalo", "uma grande bobagem", reforçando tanto os achados de Recuero e Soares (2013) a respeito das tentativas de redução do impacto da violência e de deslegitimação do pensamento crítico 
presentes na internet, como as análises de Douglas (2005) sobre a necessidade da branquitude de construir sujeitos brancos inocentes e imunes em relação à "questão" racial.

Outra maneira de relegar a constatação do preconceito no plano do indivíduo está na sugestão para resolução do problema: mudar de canal. Para os autores dos comentários, diante de tantos comentaristas esportivos e de outros canais de televisão que, na opinião deles, não reproduzem as falas levantadas no texto, os discursos considerados racistas e machistas são relativizados e não tão danosos. Em contrapartida, e relembrando Fanon (2008), o que está em jogo na colonização, nesse caso dos corpos das atletas negras representado pela tenista, é sempre um processo de transformar seres humanos em objetos em uma perspectiva estrutural abrangente, generalizante e, portanto, não factual ou isolada.

O segundo comentário ao texto de Ribeiro, do usuário "MOA", recebeu cinco curtidas e apresenta uma particularidade: ele rapidamente faz questão de se eximir de não gostar de Serena Williams. É com base no seu apreço pela tenista que afirma que os argumentos da autora são uma "grande bobagem", ou seja, pelo simples fato de ele próprio admirar Serena Williams, qualquer declaração de fundo racista ou machista proferido contra ela e, consequentemente, uma crítica a essa declaração, não devem ser levadas a sério. Essa perspectiva, que parte de sua experiência pessoal, diz respeito a dois aspectos que Bonilla-Silva (2014) analisa como sendo característicos das relações raciais na contemporaneidade: a minimização e a naturalização do racismo. "MOA" não observa qualquer preconceito ou discriminação racial nas transmissões televisivas das partidas de Serena Williams. O que mostra que os discursos sobre a tenista são tão naturalizados que ele não percebe qualquer dissonância entre o que considera como "elogios à força e à beleza" de Serena e os possíveis estereótipos adjacentes a essas considerações.

Além disso, na interação com a usuária "Mirian", a qual reforça os pontos elencados por Ribeiro, "MOA" reitera uma visão personalista ao afirmar que no canal de TV em que ele assiste não há comentários pejorativos, o que, por si só, invalidaria qualquer crítica à perseguição sofrida por Serena em outros contextos.

Esses discursos apontam para uma característica das "ficções sinceras" apontada por Spencer (2012): a elaboração de "mitologias pessoais" enquanto pessoas não preconceituosas, ou seja, a presunção de inocência que as pessoas brancas alegam instantaneamente no momento em que são interpeladas em situações de preconceito. Desse modo, observa-se uma tentativa de se mostrar isento em relação à responsabilidade pela supremacia branca, ao mesmo tempo em que se ofuscam as desigualdades raciais evidenciadas.

\subsection{Olhares sobre os corpos de atletas brancas e negras}

Análise do texto de Cleto (2009) e seus comentários

No segundo texto, o que chama a atenção são as imagens que Paulo Cleto utiliza para ilustrar sua coluna. São duas fotos, uma ao lado da outra, de Serena Williams e Dinara Safina, que disputavam a liderança do ranking internacional naquele ano. A atleta branca Dinara Safina é apresentada com uma foto de rosto, de frente, provavelmente disputando uma partida e com expressão de sofrimento, reiterado pela legenda da foto: "Dinara sofrendo". Já Serena Williams aparece de costas e de biquíni, obviamente não praticando o esporte e fora das quadras, em um jogo de luz e ângulo que centraliza e realça suas nádegas. A legenda da foto é "Serena de 
pinky", em alusão jocosa tanto à cor do biquíni da foto, quanto à saia cor-de-rosa que a atleta costuma utilizar nas quadras, a qual o autor considera "uma ofensa ao bom gosto"2.

Não se trata de dizer que as fotos foram montagens elaboradas pelo autor do texto; elas foram tiradas em outros contextos e estão disponíveis na internet. O que está em questão é a pertinência da escolha - essa sim deliberada por Cleto - em ilustrar seu texto com a justaposição dessas duas imagens. De um lado, a tenista branca que sofre, apesar do esforço, na defesa dos títulos, e, do outro, a representação da tenista negra com enfoque exclusivamente voltado ao seu corpo hipersexualizado e distante do contexto de disputa esportiva.

Se a tenista branca é mostrada em meio ao seu esforço enquanto esportista, a tenista negra não é considerada no mesmo contexto, uma vez que a visão que se tem de suas formas corporais é a característica a ser considerada. Além disso, a escolha por essa foto de Williams evidencia uma sexualidade inexistente na foto de Safina. Se há um discurso sexista na fala de Cleto - dada a inconsistência dos critérios elaborados pela WTA, ele prefere desacreditar as jogadoras e o tênis feminino como um todo do que criticar a instituição que o regulamenta -, os olhares, em forma de texto e imagem, destinados à Serena Williams revelam o olhar da supremacia branca sobre os corpos das mulheres negras e brancas. Um olhar que nada tem de novo, uma vez que não está distanciado das "miradas" (FERREIRA; HAMLIM, 2010) sobre o corpo de Sarah Baartman no século XVIII, mas, pelo contrário, persiste e se atualiza em contextos atuais.

Isso fica ainda mais evidente quando consideramos alguns dos 152 comentários sobre esse texto, exemplificados abaixo. Vale ressaltar que a caixa de comentários desse texto, bem como do blog em geral, se assemelha a um fórum de debate sobre o tênis cujo conteúdo das discussões muitas vezes ultrapassa o assunto da postagem. No que concerne ao objetivo deste artigo, alguns deles se referiam diretamente à foto de Serena com insinuações sexuais em relação ao seu corpo e cujo "fascínio erótico" será analisado posteriormente. Já outros faziam diversas referências a histórias de bastidores sobre algumas tenistas citadas por Cleto:

Figura 2 - Seleção de comentários do texto de Cleto

pov
O tenis feminino tá de dar dó, realmente.
Mas uma coisa Cleto. A Ivanovic só disse que terminou a temporada agora. Aquelas
noticias que sairam após o USO podem até terem sido premonitórias, mas sairam de uma
confusão da imprensa sérvia, não de nenhuma palavra dela. Um dia depois de sair a
noticia, teve uma nota no site dela esclarecendo a confusão... em fim, a Aninha é um mar
de dúvidas e falta de confiança, mas ainda não chegou a se contradizer a esse ponto não..
Mas agora vai ficar a impressão que ela fala coisas, volta atrás e se contradiz, por um erro
de um tablóide serrvio.. A moça já está mal, ainda pioram.
Ricardo
Boa noite.. me permita..
A Aninha ta precisando de colinho.. a verdade é que o Verdasco tirou essa minina do eixo..
isso sim...
Alguem se habilita a dar colo a Ana?

Fonte: CLETO, 2009.

2 Após um intenso debate entre os autores desse artigo, bem como junto a pares em congressos científicos e no âmbito de grupos de estudos, optou-se por não apresentar a imagem da atleta de biquíni neste artigo. Isso porque, além dessa imagem já estar disponível na internet no link referenciado, levou-se em consideração o compromisso de não endossar a representação visual elaborada pelo autor da coluna, visto que só contribui para a reificação dos corpos das mulheres negras. Motivo pelo qual também se optou por não apresentar nenhuma imagem ou representação gráfica de Sarah Baartman. 
Nos comentários a tenista Ana Ivanović é tratada no feminino e no diminutivo, seu apelido é "Aninha". Já Serena Williams, em outros momentos, é tratada no masculino e aumentativo: "Serenão". Ana Ivanović é tratada com compreensão pelos comentaristas quanto aos motivos de seu abandono das competições e suas declarações correlatas. 0 comentarista "Ricardo" ainda acrescenta que a tenista necessita de apoio emocional por conta do namoro com o também tenista Fernando Verdasco e pergunta, como se fosse uma obviedade, quem estaria interessado em oferecê-lo. Para Serena, no entanto, os sentimentos dirigidos são de outra ordem:

Figura 3 - Seleção de comentários do texto de Cleto

Sidney
Cleto
Contam uma estória por aí, que voce pode confirmar, que a Serena teria tentado namorar
com o Guga, dando até uns CDs para ele, que depois do foram, foram devolvidos.
Isso é verdade?
Já imaginaram... aquele varapau andando por aí com essa aBUNDAncia?
Sidney
paulocleto
Tentar tentou, mas, dizem, o mané resistiu, bravamente.
Matteoni
Seria um caso de amor digno do Sítio do Pica-Pau Amarelo:
Visconde de Sabugosa \& Cuca!!!
césar cambuí
Muito boa.

Fonte: CLETO, 2009.

"Sidney" traz à tona um boato sobre um suposto flerte de Serena Williams com o tenista brasileiro Gustavo Kuerten, ao que "paulocleto", o autor do texto, responde que só não ocorreu porque Guga "resistiu bravamente". Ou seja, no discurso dos comentaristas, não há dúvidas de que alguém queira "dar colo" a uma esportista branca e desprezar uma atleta negra. É possível analisar novamente como o discurso que hierarquiza por gênero se distingue e aprofunda a dinâmica da violência quando se trata de uma mulher negra. "Matteoni" complementa a história com seu comentário e expõe que, nesse improvável relacionamento, haveria duas figuras pitorescas: de um lado, um homem branco, magro, alto, loiro, de cabelos cacheados e que encarna uma sabedoria; do outro, uma mulher-monstro. Ainda que as duas personagens sejam do universo do fantástico e do sobre-humano, somente à Serena cabe o papel do corpo desumanizado.

Schultz (2005), ao analisar comentários da imprensa a respeito da vestimenta utilizada por Serena Williams, afirma que, embora a utilização por atletas de roupas que desafiam as normas de gênero no tênis tenha ocorrido diversas vezes na história da modalidade, as narrativas sobre o traje, e a corporeidade de Serena nele, variam do fascínio erótico ao desprezo, dada a ênfase que dão aos seus músculos e formas corporais. Nesse sentido, com base nessa especulação acerca do envolvimento de Guga com Serena, bem como nos comentários feitos à foto ilustrativa do texto de Cleto, é possível cogitar uma suposta tentação, 
imaginada pelos comentaristas, do tenista Guga diante da possibilidade de se relacionar com Serena. Tal consideração remeteria a esse fascínio erótico do corpo negro sob o olhar da branquitude: 0 apelo ao erótico, nesse contexto, não se remete à horizontalidade do afeto, mas ao âmbito de uma colonização sexual. O sexo é encarado nesse diálogo a partir de uma lógica de "exploração" sexual, algo percebido como inevitável diante do corpo considerado como "outro". Assim, embora nessa situação o corpo da tenista seja objetificado de uma forma diferente, denotando fascínio e uma espécie de atração "instintiva" pelo corpo negro, mais uma vez, evidencia-se a sua dimensão biológica e sua hipersexualização.

\subsection{Olhares sobre as performances de atletas brancas e negras}

Análise dos comentários de uma vitória (UOL, 2015) e uma derrota (ESPN, 2015) de Williams e sobre a questão do doping (UOL, 2016)

As notícias do portal UOL (SERENA..., 2015b), sobre a vitória de Serena em Wimbledon pela sexta vez, e do site ESPN (SERENA..., 2015a), sobre uma derrota para uma tenista menos experiente, geraram, respectivamente, 24 e 22 comentários, sendo os mais representativos da totalidade e/ou os mais curtidos e comentados apresentados abaixo. Convém destacar em relação à matéria do UOL (SERENA..., 2015b) que os comentários apresentados, que reiteram conteúdos semelhantes, representam uma quantidade significativa (mais de 20\%) do total. No texto da ESPN (SERENA..., 2015a), por sua vez, o comentário selecionado foi 0 mais aprovado (com maior número de curtidas) e também o mais comentado por pessoas que, majoritariamente, se opuseram a ele, inclusive alegando racismo. Em ambos os textos houve pessoas que comentaram em apoio a Serena Williams ou comentaram aspectos gerais do jogo e da temporada daquele ano:

Figura 4 - Seleção de comentários do texto de UOL (2015)




Figura 5 - Seleção de comentários do texto de ESPN (2015)

João Carlos Garcia

Arquiteto at Construtora Norberto Odebrecht S A

$\mathrm{O}$ que vimos hoje foi uma grande liçăo que a vida dá em todos os arrogantes e soberbos... NINGUÉM ganha nada na véspera! O povo americano, ao esgotar as entradas da final feminina muito antes da mesma acontecer, demonstrou a arrogância e prepotência que lhe são peculiares. A lutadora de boxe disfarçada de tenista, mesmo sendo colocada na chave mais furreca do torneio, năo conseguiu ir adiante, năo foi páreo para o jogo estratégico e quase sem erros da italiana. PARABÉNS a Vinci, que năo se intimidou com aqueles gritos escandalosos de " come on " caracteristicos de quem tenta amendrontar as adversárias, e muitas vezes consegue, só que hoje a casa caiu bonito!

Curtir - Responder ' $B 12 \cdot 11$ de setembro de 2015 12:30

Fonte: SERENA..., 2015a.

Constatou-se que em ambas as situações, ou seja, vitória ou derrota, o discurso que se pauta pela lógica da supremacia branca sem mencionar termos raciais se faz presente. Nessas situações, em que o centro da discussão é o jogo e a performance corporal das atletas, estabelece-se uma relação que hierarquiza de acordo com a raça. $O$ discurso da supremacia branca é operacionalizado tanto para deslegitimar a vitória, quanto para valorizar a derrota de modo a ratificar os lugares de poder de atletas brancas em um esporte também considerado branco.

Destacam-se os comentários de "Msouzafon" ao afirmar que Serena Williams "bate" nas rivais, as quais considera "normais". Em outras palavras, o comentarista, ao mesmo tempo em que julga a tenista em termos de anormalidade, escolhe um verbo que remete a uma atitude agressiva, uma vez que avalia a corporeidade de Serena como discrepante, aludindo à possibilidade de dopagem. Já "BOTA NELES" questiona a condição da atleta enquanto mulher alegando, sem qualquer evidência, uma superdosagem hormonal não investigada. "The Ripper" e "asde", por sua vez, reiteram o argumento da "anormalidade" em relação ao ser mulher levantado pelos outros comentaristas. Já "c.a.t.r.a.c.a." retoma uma fala de Shamil Tarpichev, presidente da Federação Russa de Tênis, punido pela WTA por ter se referido a Venus e Serena Williams como "irmãos" (CARTOLA..., 2014), reforçando as considerações de Mills (2003) a respeito do caráter global da supremacia branca.

Essa reiteração de comentários questionando a condição de Serena enquanto mulher expõe outra linha discursiva característica da supremacia branca: a compreensão e codificação dos corpos de mulheres negras a partir de noções de masculinidade. A partir de estereótipos sobre a resistência física, as mulheres negras, especialmente as atletas, estariam mais próximas ao que é considerado "masculino" do que ao "feminino" (SCHULTZ, 2005). Sob essa perspectiva, a atribuição de Serena Williams como "superatleta" nos comentários evidencia uma excepcionalidade que pouco tem a ver com sua potencialidade atlética e muito mais com as concepções hierarquicamente racializadas sobre corpos negros e brancos.

Assim, a desumanização é patente ao considerar Serena Williams como fora da normalidade em relação aos padrões femininos, mesmo que haja, nos circuitos mundiais de tênis, atletas aparentemente tão fortes fisicamente quanto ela, como Marion Bartoli e Samantha Stosur ou mesmo a ex-tenista Martina Navratilova, considerada nos rankings da WTA, juntamente com Serena Williams, uma das melhores tenistas de todos os tempos. 
Sobre a questão do doping, são notórias as diferenças de tratamento quando os comentaristas se remetem a Serena Williams, cujas acusações não ultrapassam a especulação, e a Maria Sharapova, uma das principais adversárias de Williams, que foi flagrada, no início de 2016, no exame antidoping com uma substância proibida. A notícia do UOL (SHARAPOVA..., 2016) referente ao ocorrido recebeu 69 comentários, dos quais destacamosalguns pela reiteração do discurso. Os outros comentários desse texto variaram entre as seguintes linhas narrativas: desaprovação moral da tenista; estabelecimento de relações entre a alegada honestidade da tenista em assumir o doping e o cenário político-partidário brasileiro; ou especulação que essa situação seria mais uma das "desculpas" (justificáveis) que atletas estariam utilizando à época para não participar dos Jogos Olímpicos de 2016, em meio à epidemia do vírus Zika no Brasil.

Figura 6 - Seleção de comentários do texto de UOL (2016)

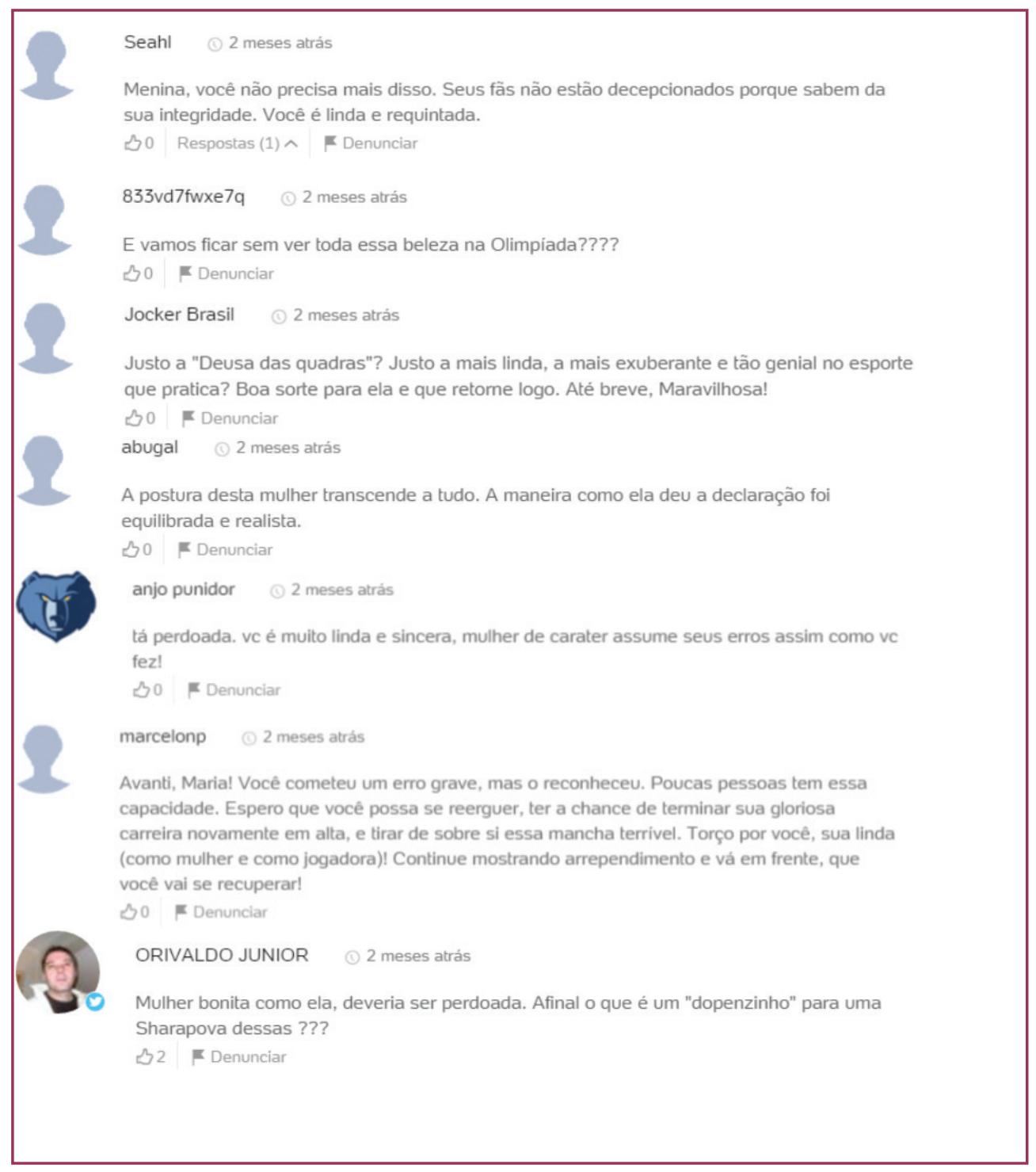

Fonte: SHARAPOVA..., 2016

O doping comprovado de Sharapova é atenuado e até perdoado pelos comentaristas de diversas maneiras. Quer seja pela alegação estética, quer seja pela via moral. 0 amparo que a tenista russa recebe difere da condenação pública sofrida por Serena Williams. Em outras palavras, a valorização estética e ética da branquitude de Maria Sharapova confere a ela dividendos sociais em detrimento da negritude de Serena Williams. O que mostra que a 
supremacia branca reserva às pessoas de cor de pele branca uma série de amparos sociais que se tornam privilégios e vantagens em relação às pessoas de cor de pele negra.

Parece estar fora de cogitação para os comentaristas considerar que Serena treinou de forma programada para atingir tal nível atlético e que sua corporeidade é resultado desse treinamento e, por isso, condição a ser valorizada esportivamente. Além disso, ignoram que Williams alia sua força muscular com habilidade técnica. Desse modo, ao considerarem essa característica corporal como próximo do atávico, do "natural" - e, por ser natural, característico de toda sua "raça" em sentido biológico, tal qual era considerada Sarah Baartman - e não fruto de treinamento de excelência, os comentaristas afirmam que só restariam recursos ilegais ou a troca de categoria para que a competitividade (ou a normalidade) com as atletas brancas pudesse ser restabelecida.

Já em relação à derrota da tenista negra, o comentário de "João", aprovado por outros 12 leitores, aponta para características morais implicadas na relação estabelecida entre Serena Williams e suas adversárias nas partidas. Há uma reiteração de sua desqualificação enquanto tenista ("lutadora de boxe disfarçada de tenista"). Na visão do comentarista, a "brutalidade" do boxe, esporte notadamente praticado por atletas negros, se opõe à "delicadeza" do tênis. Isso dá amparo a um contraponto com a atleta italiana que derrota Serena, e que possui "jogo estratégico e quase sem erros". Trata-se de um jogo de opostos entre técnica, construída no âmbito da cultura, e a força bruta, da ordem da natureza.

Além da oposição no âmbito técnico do jogo, o comentarista alude para as comemorações feitas por Serena em cada ponto ganho. Para ele, tal fato expressa uma intenção de impor medo, de intimidar, acompanhando o que identifica como arrogância da torcida estadunidense pela jogadora. Essa posição revela uma intenção de relegar a Serena uma estratégia desleal a partir da sua aludida força física superior, entendida como sua única capacidade. Mesmo sendo comuns em muitas partidas de tênis e compreensíveis em uma partida acirrada valendo um torneio importante, o entendimento dos "gritos" e comemorações de Serena como tentativas de se impor pela força, de "ganhar no grito", é também racializado, com base em percepções falaciosas sobre a fragilidade de corpos de mulheres brancas em contraposição à "agressividade" dos corpos de mulheres negras. Assim, em uma demonstração de solidariedade racial (DOUGLAS, 2005), a posição do comentarista sobre a vitória de Roberta Vinci simboliza uma ideia de triunfo na superação daquilo que "amedronta"; do sentimento que a branquitude na colonização possui: o medo do biológico encarnado nos corpos negros (FANON, 2008).

\section{CONSIDERAÇÕES FINAIS}

A análise dos textos e comentários sobre Serena Williams na internet permitiu identificar três aspectos recorrentes do discurso da supremacia branca no âmbito do esporte, em especial do tênis:

- A elaboração de "ficções sinceras", ou seja, a construção argumentativa utilizada para, primeiramente, se eximir de qualquer relação com atitudes preconceituosas, para, em seguida, não reconhecer a existência da supremacia branca e das manifestações de hierarquização racial, mesmo após demonstração de evidência contrária. Tal estratégia ampara a ocorrência de novos ataques com base na hierarquização racial, uma vez que 
deslegitima os discursos críticos à supremacia branca.

- Em um contexto de desigualdade de gênero, os corpos das atletas brancas são vistos como delicados e sensuais, enquanto que os das atletas negras são hipersexualizados e desumanizados.

- A hierarquização das performances de atletas negras(os) e brancas(os), aproximando as primeiras do atávico e da natureza, enquanto que as segundas são consideradas em suas habilidades técnicas, táticas e estratégicas, adquiridas, portanto, próximos da ordem da cultura e civilização.

Desse modo, concluímos que a supremacia branca está presente no esporte mesmo quando não há referências diretas à raça ou manifestações de ódio racial a atletas não brancos, ou seja, esse sistema de dominação baseado na raça não se revela apenas a partir de ações excepcionais e individuais, mas está disposto no cotidiano das relações sociais no esporte e estruturam seus locais de poder e saber. Com relação aos estudos sobre o tênis que tratam sobre as narrativas circulantes sobre atletas, observamos que são utilizadas estratégias e argumentações discursivas semelhantes às analisadas neste artigo, a fim de amparar a supremacia branca (em um contexto geral e, especificamente, nessa modalidade esportiva). Uma vez que a maioria desses estudos é oriunda de países de língua inglesa, é possível afirmar que caracterizam um modo de compreender as relações raciais na contemporaneidade que, apesar das especificidades históricas, políticas e sociais das colonizações nos diferentes locais, transcendem as fronteira nacionais e regionais e expõem o caráter global da supremacia branca (MILLS, 2003; BONILLA-SILVA, 2014). Além disso, o esporte é um local de produção de discursos que sustentam essa supremacia e a violência correlata. Isso porque reiteram argumentações pautadas na biologia e nos essencialismos culturais, contribuindo para interpretações sobre o protagonismo atlético de esportistas negros e negras, em relação aos atletas brancos e brancas, que revisitam mitos construídos pelo racismo científico do século XIX (SCHUCMAN, 2014).

Frente à violência a que são submetidos os corpos negros em uma sociedade de supremacia branca, compreender o que ampara tal violência, assim como sua justificativa e a ausência de comoção social, expondo os itinerários discursivos da branquitude, é uma tarefa urgente. Foi sob essa perspectiva que o presente artigo se propôs a analisar a persistência e reprodução desse sistema de poder no esporte a partir de comentários veiculados na internet.

O esporte, em especial o tênis, se mostrou como um campo profícuo para essa análise, uma vez que nele corpos brancos e negros estão em evidência e os discursos sobre eles abrangem desde o sentido biológico até o moral. Do mesmo modo e sustentado por evidências já relatadas em outros estudos (RECUERO; SOARES, 2013; ASSUNÇÃO; MATOS, 2014; BIONDO, 2015), constatou-se que a rede mundial de computadores, em especial a seção de comentários de publicações na internet, revelou-se ser um espaço de enunciação de discursos voluntários de preconceito e de ódio, em grande medida estimulados pelo anonimato e pela ausência de comprometimento com o diálogo face a face. 


\section{REFERÊNCIAS}

ASSUNÇÃO, Raquel Sofia; MATOS, Paula Mena. Perspectivas dos adolescentes sobre o uso do Facebook: um estudo qualitativo. Psicologia em Estudo, v. 19, n. 3, p. 539-547, jul./set. 2014.

BENTO, Maria Aparecida Silva. Branqueamento e branquitude no Brasil. In: CARONE, Iray; BENTO, Maria Aparecida Silva. (Org.). Psicologia social do racismo: estudos sobre branquitude e branqueamento no Brasil. Petrópolis: Vozes, 2002. p. 25-57.

BIONDO, Fabiana Poças. "Liberte-se dos rótulos": questões de gênero e sexualidade em práticas de letramento em comunidades ativistas do Facebook. Revista Brasileira de Linguística Aplicada, v. 15, n. 1, p.209-236, jan./mar. 2015.

BIRREL, Susan. Racial relations theories and sport: suggestions for a more critical analysis. Sociology of Sport Journal, v. 6, n. 3, p. 212-227, sept.1989.

BONILLA-SILVA, Eduardo. Racism without racists: color-blind racism and the persistence of racial inequality in the United States. Lanham: Rowman and Littlefield, 2014.

BOURDIEU, Pierre. Como se pode ser esportista? In: BOURDIEU, Pierre. Questões de sociologia. Lisboa: Fim de Século, 2004b. p. 181-203.

BOURDIEU, Pierre. Programa para uma sociologia do esporte. In: BOURDIEU, Pierre. Coisas ditas. São Paulo: Brasiliense, 2004a. p. 207-220.

CARNEIRO, Maria Luiza Tucci. Metáforas roubadas à doença: particularidades do discurso racista. In: MONTEIRO, Yara Nogueira; CARNEIRO, Maria Luiza Tucci (Org.). As doenças e os medos sociais. São Paulo: Editora Fap-Unifest, 2012. p. 251-267.

CARRINGTON, Ben. The critical sociology of race and sport: the first fifty years. Annual Review of Sociology, v. 39, p. 379-398, 2013.

CARTOLA russo é punido por chamar Venus e Serena de "irmãos". 2014. Disponível em: $<\underline{h t t p: / /}$ esportes.terra.com.br/tenis/cartola-russo-e-punido-por-chamar-venus-e-serena-de-irmaos,34f00dc16b 229410VgnCLD200000b2bf 46dORCRD.html>. Acesso em: 16 fev. 2016.

CLETO, Paulo. Saco de gatas. 5 out. 2009. Disponível em: <http://paulocleto. ig.com.br/index. php/2009/10/05/saco-de-gatas/>. Acesso em: 3 nov. 2015.

CRUZ JUNIOR, Gilson; FERMINO, Antonio Luis; PIRES, Giovani de Lorenzi. O Brasil na Copa, a Copa no Brasil: notas sobre o agendamento midiático da Copa de 2014 no Blog do Juca. Revista Brasileira de Ciências do Esporte, v. 37, n. 3, p. 251-257, set. 2015.

DOUGLAS, Delia D. To be young, gifted, black and female: a meditation on the cultural politics at play in representations of Venus and Serena Williams. Sociology of Sport Online, v. 5, n. 2, nov./dec. 2002. Disponível em: <http://physed.otago.ac.nz/sosol/v5i2/v5i2 3.html>. Acesso em: 2 maio 2016.

DOUGLAS, Delia D. Venus, Serena, and the inconspicuous consumption of blackness: a commentary on surveillance, race talk, and new racism(s). Journal of Black Studies, v. 43, n. 2, p. 127-145, mar. 2012.

DOUGLAS, Delia D. Venus, Serena, and the women's tennis association: when and where "race" enters. Sociology of Sport Journal, v. 22, n. 3, p. 255-281, set. 2005. 
FANON, Frantz. Pele negra, máscaras brancas. Salvador: EDUFBA, 2008.

FERREIRA, Jonatas; HAMLIN, Cynthia. Mulheres, negros e outros monstros: um ensaio sobre corpos não civilizados. Revista Estudos Feministas, v. 18, n. 3, p. 811-836, 2010.

FONSECA, Leandro Campos. Estudo de caso dos repertórios interpretativos empregados na construção de posicionamentos contrários ao sistema de cotas raciais nas universidades públicas brasileiras em comentários de internet. 2014. 251f. Dissertação (Mestrado em Psicologia Social) - Instituto de Psicologia, Universidade de São Paulo, São Paulo, 2014.

GIRARDET, Raoul. Mitos e mitologias políticas. São Paulo: Companhia das Letras, 1987.

GRESPAN, Carla Lisboa; GOELLNER, Silvana Vilodre. Fallon Fox: um corpo queer no octógono. Movimento, v. 20, n. 4, p. 1265-1282, out./dez. 2014.

HARTMANN, Douglas. What can we learn from sport if we take sport seriously as a racial force? Lessons from C.L.R. James's Beyond a Boundary. Ethnic and Racial Studies, v. 26, n. 3, p. 451-483, may 2003.

HYLTON, Kevin. Race and Sport: critical race theory. Londres: Routledge, 2008.

IFEKWUNIGWE, Jayne O. Venus and Serena are "doing it" for themselves: theorizing sporting celebrity, marxism and black feminism for "the hip-hop generation". In: CARRINGTON, Ben; MCDONALD, Ian (Ed.). Marxism, cultural studies and sport. London: Routledge, 2009. p. 130-153.

JAMES, Cyril Lionel Robert. Beyond a boundary. Durham: Duke University Press, 1993.

MLLLS, Charles W. White Supremacy as sociopolitical system: a philosophical perspective. In: BONILLA-SILVA, Eduardo; DOANE, Ashley "Woody" (Ed.). White out: the continuing significance of racism. London: Routledge, 2003. p. 35-48.

RECUERO, Raquel; SOARES, Priscila. Violência simbólica e redes sociais no Facebook: o caso da fanpage "Diva Depressão". Galaxia, n. 26, p. 239-254, dez. 2013.

RIBEIRO, Djamila. Comentaristas esportivos: respeitem Serena Willians. 26 jun. 2015. Disponível em: <http://www.cartacapital.com.br/sociedade/comentaristas-esportivos-respeitem-serenawillians-7812.html>. Acesso em: 4 nov. 2015.

SCHUCMAN, Lia Vainer. Branquitude e poder: revisitando o "medo branco" no século XXI. Revista da ABPN, v. 6, n. 13, p. 134-147, mar./jun. 2014.

SCHUCMAN, Lia Vainer. Entre o "encardido", o "branco" e o "branquíssimo": raça, hierarquia e poder na construção da branquitude paulistana. 2012. 122f. Tese (Doutorado em Psicologia Social) Instituto de Psicologia, Universidade de São Paulo, São Paulo, 2012.

SCHULTZ, Jaime. Reading the catsuit: Serena Williams and the production of blackness at the 2002 U.S. Open. Journal of Sport and Social Issues, v. 29, n. 3, p. 338-357, aug. 2005.

SERENA leva virada improvável na semifinal e perde maior chance de fazer o Grand Slam. 11 set. 2015a. Disponível em: <http://espn.uol.com.br/noticia/542502 serena-leva-virada-improvavel-nasemifinal-e-perde-maior-chance-de-fazer-o-grand-slam>. Acesso em: 4 nov. 2015.

SERENA vence em Wimbledon pela sexta vez e completa o 'Serena Slam'. 11 jul. 2015b. Disponível em: <http://esporte.uol.com.br/tenis/ultimas-noticias/2015/07/11/serena-vence-em-wimbledon-pelasexta-vez-e-completa-o-serena-slam.htm>. Acesso em: 4 nov. 2015. 
SHARAPOVA anuncia que foi pega em exame antidoping e está suspensa. 7 mar. 2016. Disponível em: <http://olimpiadas.uol.com.br/noticias/2016/03/07/sharapova-anuncia-em-coletiva.htm>. Acesso em: 10 mar. 2016.

SPENCER, Nancy E. Sister Act VI: Venus and Serena Williams at Indian Wells: "sincere fictions" and white racism. In: LEONARD, David J.; KING, C. Richard (Org.). Commodified and criminalized: New Racism and African Americans in contemporary sports. Lanham: Rowman and Littlefield, 2012. p. 4167. 
